\title{
Lidar observations and numerical simulations of an atmospheric hydraulic jump and
} mountain waves

\author{
Peña, Alfredo; Santos, P.
}

Published in:

Journal of Geophysical Research: Atmospheres

Link to article, DOI:

10.1029/2020JD033744

Publication date:

2021

Document Version

Peer reviewed version

Link back to DTU Orbit

Citation (APA):

Peña, A., \& Santos, P. (2021). Lidar observations and numerical simulations of an atmospheric hydraulic jump and mountain waves. Journal of Geophysical Research: Atmospheres, 126(4), [e2020JD033744].

https://doi.org/10.1029/2020JD033744

\section{General rights}

Copyright and moral rights for the publications made accessible in the public portal are retained by the authors and/or other copyright owners and it is a condition of accessing publications that users recognise and abide by the legal requirements associated with these rights.

- Users may download and print one copy of any publication from the public portal for the purpose of private study or research.

- You may not further distribute the material or use it for any profit-making activity or commercial gain

- You may freely distribute the URL identifying the publication in the public portal

If you believe that this document breaches copyright please contact us providing details, and we will remove access to the work immediately and investigate your claim 


\title{
Lidar observations and numerical simulations of an atmospheric hydraulic jump and mountain waves
}

\author{
A. Peña ${ }^{1}$ and P. Santos ${ }^{1}$ \\ ${ }^{1}$ DTU Wind Energy, Technical University of Denmark, Frederiksborgvej 399, 4000 Roskilde, Denmark
}

Key Points:

- A distinct atmospheric hydraulic jump over the Alaiz mountain range and Elorz valley in northern Spain is observed from radial velocity retrievals performed with two scanning lidars

- We are able to simulate the hydraulic jump in qualitatively high detail and agreement with the observations using the multi-scale capabilities of the Weather Research and Forecasting model

- Two main types of mountain waves or flow regimes are identified under upstream conditions with Froude numbers larger than unity by studying the ratio of the depthaverage mean wind speed to the depth-average Brunt-Väisälä frequency both upstream and downstream of the mountain top

Corresponding author: Alfredo Peña, aldi@dtu.dk

This article has been accepted for publication and undergone full peer review but has not been through the copyediting, typesetting, pagination and prodfreading process, which may lead to differences between this version and the Version of Record. Please cite this article as doi: 10.1029/2020JD033744.

This article is protected by copyright. All rights reserved. 


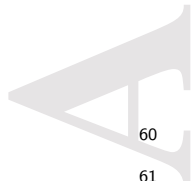

\begin{abstract}
An atmospheric hydraulic jump was observed over the Alaiz mountain range and Elorz valley near Pamplona, Spain from radial velocity retrievals performed with two scanning lidars during October 5 and 6, 2018. The jump occurred on the lee side of the mountain close to its base and the jump location was observed more than two kilometers further downstream of the mountain base inside the valley. Here, we simulate the two days using the multi-scale modeling capabilities of the Weather Research and Forecasting model. We find that the model is able to reproduce the hydraulic jump in high detail matching qualitatively well the timing and main features observed by both the scanning lidars and meteorological instruments on masts deployed throughout the area. The simulation results shows that the jump starts at the beginning of the evening, right after the atmospheric conditions over the top of the Alaiz mountain become stable and the flow at the mountain top experiences a transition from subcritical to supercritical. The simulations also show that the jump lasts about 10 hours until it moves close to the mountain top; then lee-wave activity dominates and lasts until late in the morning. The flow at the mountain top is only supercritical during the periods where the jump and the lee waves take place. The jump and lee-wave regimes can be distinguished from the simulation results by analyzing the ratio of the depth-average Brunt-Väisälä frequency to the depth-average mean wind speed both upstream and downstream of the mountain top.
\end{abstract}

\title{
1 Introduction
}

Hydraulic jumps and other related phenomena have been studied for many decades (Rayleigh, 1883; Lyra, 1943; Long, 1953), and readers are referred to the survey of Chanson (2009) for details on the progress of experiments conducted in controlled channels mainly. Although results from theoretical studies and controlled experiments have provided us with the basis for understanding the jump mechanisms in the atmosphere, studies, and particularly, observations of atmospheric hydraulic jumps are not as common.

Clarke (1972) was perhaps the first one who attempted to combine large-scale observations with simulations to explain an atmospheric phenomenon, the "morning glory", which is a frequent squall that occurs near dawn on the southern coast of the Gulf of Carpentaria, Australia, quite recognizable due to its narrow cloud bands. He concluded that the morning glory is a propagating undular hydraulic jump formed in a katabatic flow. He also suggested some of the conditions that favor the occurrence of such phenomena, i.a., shallow inversions, steep slopes, and topographic funneling. However, observational studies of atmospheric jumps can be tracked further back (Manley, 1939; Holmboe \& Klieforth, 1957). More recently, the studies of Mobbs et al. (2005) and Gohm et al. (2008) showed the close connection between mountain waves, downslope winds, and jump events. Other recent observational and numerical studies have further detailed the conditions at which atmospheric hydraulic jumps occur (Juliano et al., 2017; Rotunno \& Bryan, 2018),

To understand how an atmospheric hydraulic jump develops, we can start by assuming, very simplistically, that the flow can be represented by a two-layer model, the lowest layer being the atmospheric boundary layer (ABL) and the upper layer the free atmosphere (Samuelson, 1992). In complex terrain, e.g., mountainous regions, the depth of the ABL, $h$, can be of the order of the terrain elevation and the nature of the flow depends upon the Froude number (Fr),

$$
\operatorname{Fr}=\frac{\langle U\rangle_{h}}{\sqrt{g_{r} h}}
$$

where \langle\rangle$_{X}$ indicates a vertical/depth average over the extent of $X, U$ is the wind speed, and $g_{r}$ the reduced gravity,

$$
g_{r}=\frac{g\left(\Theta_{T}-\langle\Theta\rangle_{h}\right)}{\langle\Theta\rangle_{h}},
$$

This article is protected by copyright. All rights reserved. 
where $g$ is the gravitational constant, $\Theta_{T}$ the free troposphere potential temperature and $\Theta$ the potential temperature. The latter two expressions assume a well-defined inversion and that both $U$ and $\Theta$ are relatively constant below $h$. Fr is defined as the ratio of the mean ABL wind speed to the fastest possible gravity wave traveling along the two-layer fluid interface (Juliano et al., 2017). When the flow experiences the transition from supercritical $(\mathrm{Fr}>1)$, e.g., on a mountain top to subcritical $(\mathrm{Fr}<1)$, e.g., on the lee side of the mountain or further downstream of the mountain base, an atmospheric hydraulic jump can develop. When the flow becomes supercritical at the mountain top, the inversion layer starts to restrict the vertical movement of the air. The ABL then thins over the leeward slope and the flow accelerates (downslope winds), until it reaches a region of reduced pressure gradient; mass convergence can eventually occur (usually close to the mountain base) and upward motion takes place. The latter is what we refer to here as a hydraulic jump.

Based on radial velocity retrievals from two scanning lidars mainly, Santos et al. (2020) illustrated an atmospheric hydraulic jump that started on a clear-sky autumnal afternoon over the Alaiz mountain range and Elorz valley in the northeast of Spain. Apart from previous results on smaller spatial scale experiments where hydraulic jumps (Lehner et al., 2016) and lee-wave activity (Palma et al., 2019) were observed and simulated, this is one of the first times in which a hydraulic jump is measured in high detail using scanning lidars. At Alaiz, the conditions are very favorable for the development of atmospheric hydraulic jumps. First, winds (southerly) on the windward slope and on top of the Alaiz mountain range are often nearly perpendicular to the ridge line; $\approx 25 \%$ of the time surface winds are south-southeast (Santos et al., 2020). Second, for southerly winds the mountain range has a gentle windward slope and a steep leeward slope. Third, geostrophic winds are strong in the region (Badger et al., 2014). Last, under southerly wind there is often a strong stable layer at the top of the Alaiz mountain (Rodrigo et al., 2013). We therefore speculate that atmospheric hydraulic jumps at Alaiz might frequently occur.

Here, we investigate the ability of the Weather Research and Forecasting (WRF) model to reproduce the atmospheric hydraulic jump observed at Alaiz and further analyze the conditions within which it develops. We start by introducing the Alaiz experiment (Sect. 2), in which the observations took place. Section 3 illustrates and details the numerical setup used for the simulations performed with the WRF model. The results with regards to the simulations and their comparison with the observations are shown in Sect. 4. Finally, discussion and conclusions are drawn in the last section.

\section{The Alaiz experiment}

The Alaiz experiment was conducted in the northeast of Spain, in an area southwest of the Pyrenees (see Fig. 1-left) as part of a set of complex-terrain experiments carried out within the New European Wind Atlas project (Mann et al., 2017). The experimental area includes the Alaiz mountain range, the Elorz valley, and the Tajonar ridge (see Fig. 1-right).

The intensive operational period took place from August 2018 to December 2018. Here, we use measurements from five meteorological masts (M2, M3, MP5, M6 and M7), which were deployed around a transect connecting the Tajonar ridge and the Alaiz mountain top (Fig. 1-right). From the 80-m tall masts (M2, M3 and M7), we use measurements from Gill WindMaster Pro sonic anemometers at 10, 20, 40, 60, and $80 \mathrm{~m}$ above ground level (agl) and from Rotronic HygroMet4 hygrometers at 2, 10, 40 and $80 \mathrm{~m} \mathrm{agl}$ (except for M3 where the hygrometer at $80 \mathrm{~m}$ was malfunctioning). From the $60-\mathrm{m}$ tall mast M6, measurements from METEK USA-1 sonic anemometers at 10, 20, 40, and 60 $\mathrm{m}$ agl and from Rotronic HygroMet4 hygrometers at 2, 10, 40, and $60 \mathrm{~m}$ agl are used. From the 118-m tall mast MP5, we use measurements from METEK USA-1 sonic anemometers at 40, 78, and $118 \mathrm{~m}$ agl and from Rotronic HygroMet4 hygrometers at 2, 40, 80, 

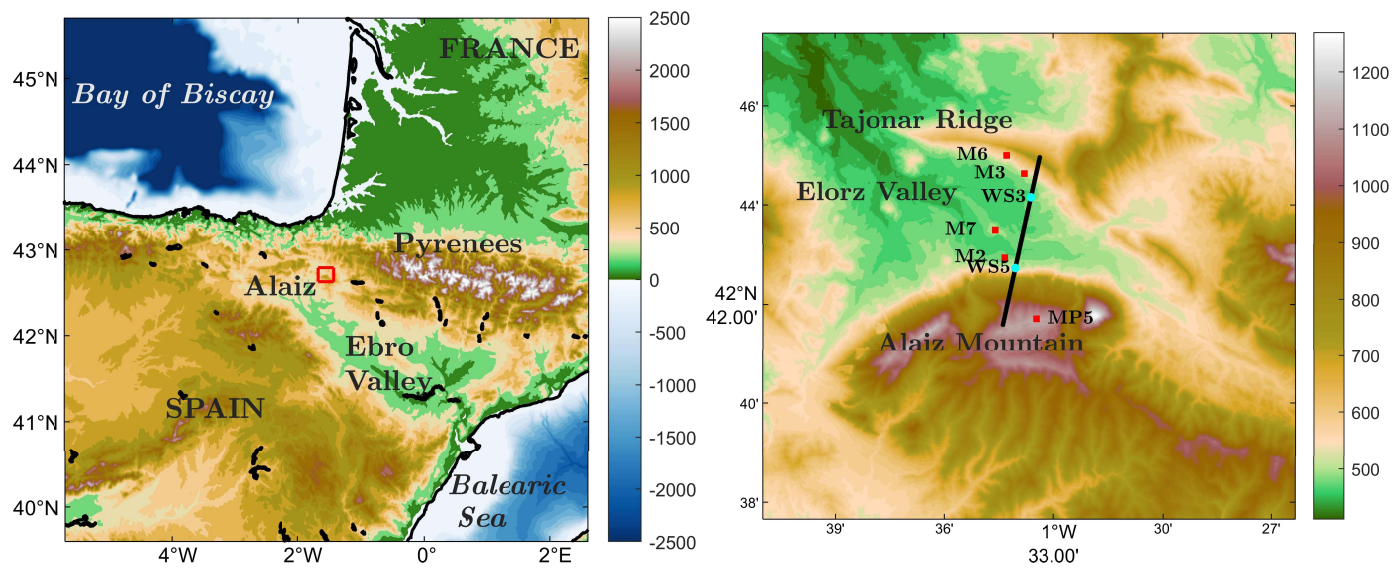

Figure 1. (Left frame) The location of the Alaiz experiment (red rectangle) in the northeast of Spain. (Right frame) A high resolution digital elevation map of the Alaiz experimental area in the red rectangle of the left frame. Black dots (nearly seen as a line) represent the locations where radial velocities were measured by two scanning lidars (cyan markers) in the Alaiz experiment. Masts are shown in red markers. The colorbar indicates the terrain elevation in meters above mean sea level

97, and $113 \mathrm{~m}$ agl. All sonic anemometer measurements were acquired at $20 \mathrm{~Hz}$ and the hygrometer measurements at $1 \mathrm{~Hz}$.

Two long-range pulsed scanning lidars (WS3 and WS5), which are modified versions of Leosphere WindCube 200S units, were also used. The lidars performed rangeheight indicator (RHI) scans along the transect connecting the Alaiz mountain range and the Tajonar ridge, i.e., the line composed by black dots in Fig. 1-right. Figure 3-bottom illustrates the RHI scans of both scanning lidars on the transect over the terrain at the Alaiz experiment. A full RHI scan, which started at a close to $2^{\circ}$ elevation and extended to about $20^{\circ}$ elevation, took $\approx 30 \mathrm{~s}$ to be completed. RHI scans were performed up to a range of $5 \mathrm{~km}$; for the WS3 the ranges were spaced $50 \mathrm{~m}$ apart and for the WS5 $20 \mathrm{~m}$ apart. The RHI scans were performed twice every hour, with other patterns being executed in between. Further details of the experiment and instrumentation are provided in Cantero et al. (2019) and Santos et al. (2020).

\section{Numerical simulation}

We performed real-time simulations using the WRF model version 4.0.1. We setup the runs with five telescopic one-way nested domains, all centered at the position of MP5 (see Fig. 2). All domains use the same amount of grid points in both horizontal directions $(240 \times 240)$ and their horizontal resolutions are, from the outermost to the innermost domain, 9000, 3000, 1000, 333.33, and $111.11 \mathrm{~m}$, respectively. The model top was set to $5000 \mathrm{~Pa}$ with 61 vertical levels, where the first 20 model levels are within the first kilometer from the surface.

The ERA5 reanalysis data at $0.3^{\circ}$ (C3S, 2018) was used to force the model together with the Operational Sea Surface Temperature and Sea Ice Analysis (Donlon et al., 2012). The CORINE land cover classification (Copernicus Land Monitoring Service, 2018) and the global multi-resolution terrain elevation data 2010 at 30 arcsec (Danielson \& Gesch, 2011) were used for the land use and for the terrain elevation, respectively. The CORINE land cover categories were reassigned to those of the US Geological Survey classification (Anderson et al., 1976), as this is included within the WRF model distribution. The top

This article is protected by copyright. All rights reserved. 


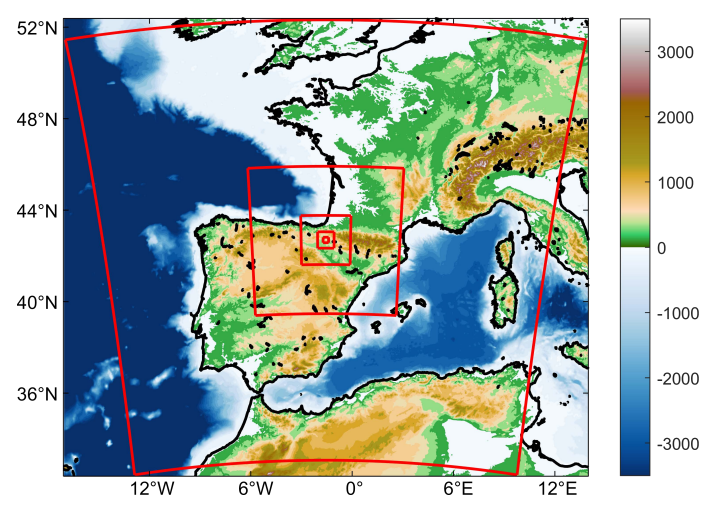

Figure 2. Telescopic nested domains (red lines) used for the WRF model simulations. All domains are centered on the meteorological mast MP5 (see Fig. 1-right) at the Alaiz mountain range. The colorbar indicates the terrain elevation in meters above mean sea level

frames in Fig. 3 illustrate both the terrain elevation and land use of the innermost domain together with the positions of the masts and lidar transect. An extended transect along that performed by the lidar scans, which is used for the analysis, is also shown. The elevation profile of the extended transect is illustrated in Fig. 3-bottom from two datasets, a 10-m digital elevation model based on lidar aerial scans and the elevation of the innermost domain of the WRF model. The main topography feature, namely the Alaiz mountain range, although smoothed, seems fairly well represented by the elevation used for the simulations, whereas the Tajonar ridge seems highly misrepresented. The Elorz valley is represented in the WRF input land cover as 'dryland cropland and pasture', most of the high elevation terrain as 'deciduous broad-leaf forest', and some elevated areas such as that where MP5 is located as 'mixed forest'. The modeled land cover is, qualitatively, in good agreement with the land cover derived from high-resolution maps (Cantero et al., 2019).

The time step used for the outermost domain was $10 \mathrm{~s}$ and the nested domains used a 1:3 time step ratio, following the grid aspect ratio. The following physics schemes were used: WRF single-moment 5-class scheme for cloud micro-physics (Hong et al., 2004), Kain-Fritsch scheme for cumulus convection (Kain, 2004) for the outermost domain only, the MYNN level 2.5 planetary boundary layer (PBL) scheme (Nakanishi \& Niino, 2009) for the three outermost domains, and the large-eddy simulation (LES) capability for the two innermost domains. The LES domains used the subgrid-scale model of Deardorff (1980) with the prognostic equation for the subgrid turbulent kinetic energy. The MYNN surfacelayer scheme (Nakanishi \& Niino, 2009) and the Unified Noah Land Surface model (Tewari et al., 2004) were used for all domains. The RRTMG scheme (Iacono et al., 2008) at 9min interval was used for the shortwave and longwave radiation.

The simulation was performed with a cold start at 00:00 UTC on October 5, 2018 and lasted for two days (all times are hereafter UTC). The simulation was nudged towards the forcing reanalysis using spectral nudging for the two horizontal wind components and temperature on the outermost domain with a constant of $0.0003 \mathrm{~s}^{-1}$. No upper level damping was used. Second-order diffusion on coordinate surfaces and two-dimensional deformation were used for the PBL domains, whereas three-dimensional turbulence mixing in physical space was used for the LES domains. All domains used a sixth-order positive definite numerical diffusion, as well as positive definite advection of moisture and scalars. Output for the innermost domain, which we use to extract the results of the WRF simulations, was produced every $10 \mathrm{~s}$. As the hydraulic jump was observed in the after-

This article is protected by copyright. All rights reserved. 

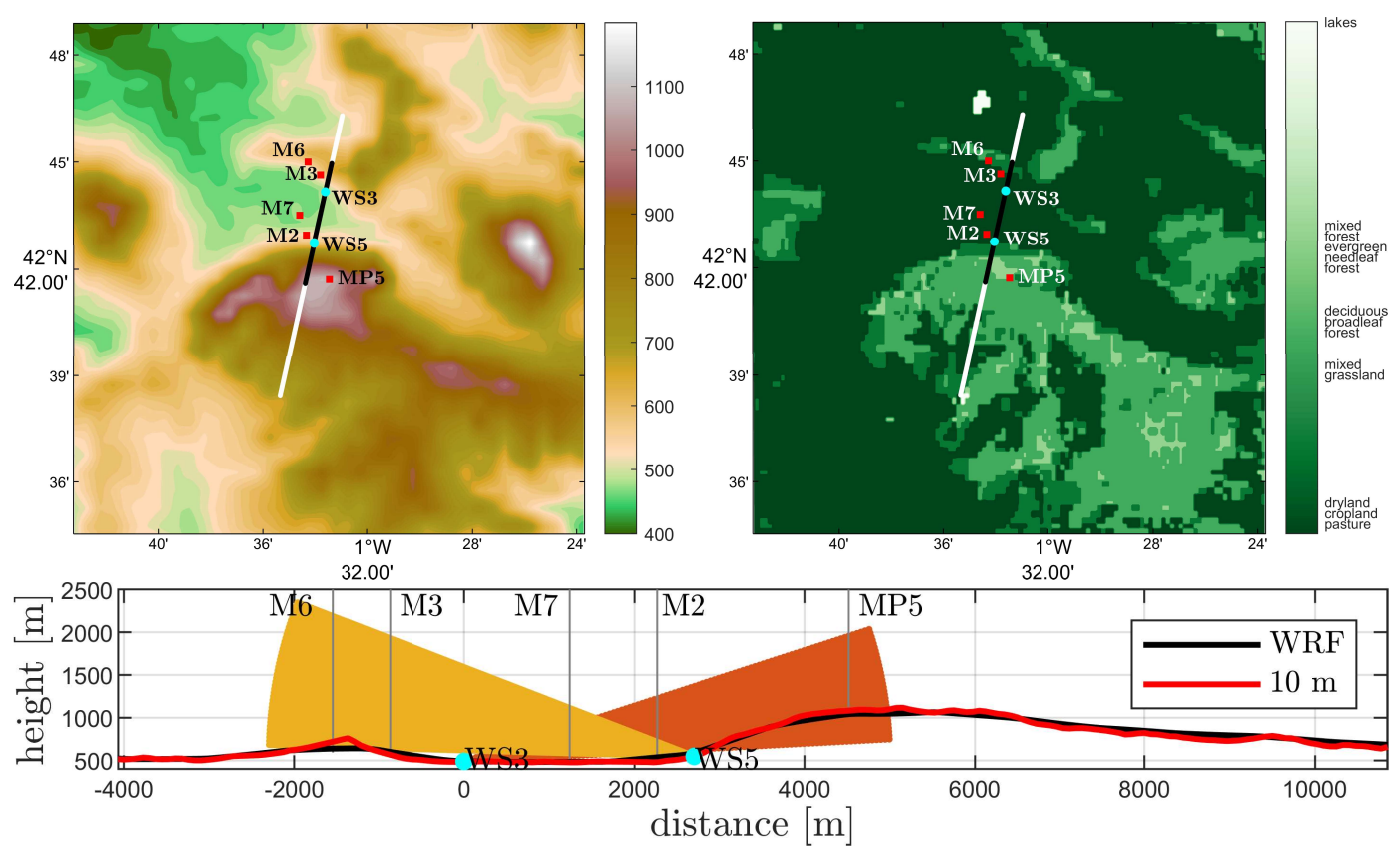

Figure 3. The terrain elevation (top left) and land cover (top right) of the innermost WRF domain. The locations of the different masts (red markers), lidar transect (black markers), and the extended transect (white markers) used for the analysis are shown. The colorbar indicates the terrain elevation in meters above mean sea level (top left) and the land cover from the US Geological Survey classification (top right). (Bottom) The elevation profile of the extended transect, where the positions of the scanning lidars (cyan markers), the WS3-RHI scan (brown markers), the WS5-RHI scan (ochre markers), and the locations of the masts projected onto the transect (grey vertical lines) are also shown

This article is protected by copyright. All rights reserved. 
noon of the first day, we assume that the model is able to adequately spin up in the hours previous to the jump event.

\section{Results}

Here we analyze the results of the simulations and their ability to capture the hydraulic jump event. We also qualitatively intercompare the simulations' results with the available measurements. When simulated time series are presented at the mast positions, the simulated variables are extracted from the grid cell closest to the masts locations. As the observations correspond to means over 10-min periods (except for the fluxes at MP5, which were computed within 30-min periods), when simulations are intercompared to observations, the 10-s outputs of the simulated variables are also time-averaged within the same concurrent period (unless otherwise stated).

An important parameter required for the computation of the Froude number in Eqn. (1) is the ABL depth. A common approach used in numerical models is based on the bulk Richardson number,

$$
\mathrm{Ri}_{b}=\left(\frac{g}{\Theta_{0}}\right) \frac{\Delta_{0} \Theta}{\Delta_{0} u^{2}+\Delta_{0} v^{2}} \Delta_{0} z,
$$

where $\Delta_{0}$ refers to the difference of a variable at a given vertical level and its value at the surface (represented by the subscript ${ }_{0}$ ), $u$ and $v$ are the two horizontal velocity components and so $U=\sqrt{u^{2}+v^{2}}$, and $z$ the height. In the $\mathrm{Ri}_{b}$-like approach, $h$ is the height at which $\mathrm{Ri}_{b}$ exceeds a critical value, $\mathrm{Ri}_{b c}$. As pointed out by Richardson et al. (2013), observational and numerical studies have shown $\mathrm{Ri}_{b c}$-values ranging from 0.1 to nearly 0.6. They argued that the range is broad due to the stability-dependence character of $\mathrm{Ri}_{b c}$, which they studied by using large-eddy simulation results and wind tunnel data.

Here, we estimate $h$ by computing $\mathrm{Ri}_{b}$ in Eqn. (3) at all simulated vertical levels and linearly interpolating between the two adjacent vertical levels at which a $\mathrm{Ri}_{b}$-value of 0.25 is reached, as traditionally performed in PBL schemes. For the analysis of the results, it is important to remind the reader that this hydraulic jump occurs over the Elorz valley and on lee side of the Alaiz mountain when the flow over its wind side and top (where MP5 is located) is south; thus M2 closely describes the lee side/downslope conditions, M7 the valley conditions, and M3 and M6 feature further downstream conditions.

It is important to note that during both days (October 5 and 6, 2018), northern and western Europe were under the influence of meandering westerlies. There was almost no background flow over the Iberian peninsula with weak synoptic-scale forcing and low-pressure systems over the English Channel and the Tyrrhenian Sea are distinguishable. The simulated surface winds over the Alaiz mountain range are southerly, as over most of the area covered by the innermost domain, but they are southeasterly and easterly on the Elorz valley. The Ebro valley forms an orographic funnel that produces two main flow patterns, with northwesterly winds (called El Cierzo) and southeasterly winds (Santos et al., 2020). The latter can be intensified when passing the gap between the Alaiz mountain range and the Tajonar Ridge. Badger et al. (2014) showed that south surface winds over the Alaiz mountain become stronger under stably stratified conditions.

\subsection{Extended transect}

A qualitative comparison of the behavior along the extended transect of both the radial velocity observed with the two scanning lidars performing RHI scans and the simulated horizontal velocity is illustrated in Fig. 4 for a number of 10-min periods during the 24-hr period covering the jump event (October 5 12:00 to October 6 12:00). Within the region where the two RHIs overlap, we use the measurements from WS5 only. Negative radial velocities indicate flow towards the north, i.e., towards WS3. For simplicity, only the hour and minute are stated hereafter; thus an event at 13:00 belongs to Oc-

This article is protected by copyright. All rights reserved. 
tober 5, whereas one at 03:00 belongs to October 6 . In the case of the observations, each period corresponds to the 10-min mean, whereas it is the instantaneous output of the model at the corresponding time.

From 01:00 on the second day until the end of the period, RHI measurements from the WS3 lidar are not available due to loss of connection to the lidar. It is important to note that these observations and model output cannot be directly compared, since the former are radial velocities, thus a scanning pattern geometry-dependent projection of the horizontal velocity (mostly) and, the latter, horizontal velocities along the transect.

The series of contours starts at 16:30, which is about the time the simulations show a wave-like pattern in the flow for the first time. One can notice, from the observations, a distinct jet (red colors indicating negative radial velocities) over the Alaiz mountain top, but in the upper part of the RHI scan a small area of positive radial velocities (blue colors) appear; such change of sign in the radial velocity indicates an ABL depth close to or lower than the mountain height, which, as we show later, is in agreement with the estimation from the simulation outputs at MP5. The ABL depth is well observed until about 21:00 when it seems to thicken with time.

From the observations at 16:30, downslope winds appear all the way through the lee side of the Alaiz mountain reaching the Elorz valley and it is not clear whether a hydraulic jump is already present. At the same time, the simulations already show a clear jump; here we first arbitrarily distinguish two types of waves, a 'hydraulic jump' from a 'mountain wave', based on the location downstream of the Alaiz mountain top of vertical movement of the air, i.e., the transition from negative (red) to positive (blue) velocities at the same vertical level; if the jump occurs downstream of the lidar at the base of the mountain (WS5), we refer to it as a jump and as lee wave otherwise. Later, we attempt to physically characterize these two regimes.

From 17:00 to 01:00, the RHIs clearly show a distinct hydraulic jump. At 17:00 the location of the jump is in the middle of the valley and at 19:00 it shifts upstream to a position close to the Alaiz mountain base. The jet then increases its strength and the jump location shifts back close to the middle of the valley until about 22:00, when the jump location shifts back to the lee side of the mountain until it cannot be distinguished in the observations from 01:00 onwards.

The shifting of the jump location is slightly different in the simulations. From 16:30 to 18:00 the jump location shifts downstream, then it moves upstream until about 20:00, downstream until 22:00, and finally shifts upstream until it reaches the mountain top. Between 01:00 and 03:00, the jump is 'replaced' by mountain-wave activity; although not shown, note that the simulations first portray a characteristic jump around 16:15, which lasts until 02:15 when vertical movement of air takes place upstream the position of WS5. After 03:00, the simulations no longer show extended downslope winds but, instead, portray wave activity with 'jumps' departing at positions close to the mountain top. As illustrated, the change in jet strength throughout the jump/mountain wave activity is qualitatively similar between both observations and simulations.

\subsection{Time development}

Figure 5 illustrates the behavior with time of the simulated wind speed at all mast locations (shown in each of the frames) within the first $\approx 1300 \mathrm{~m}$ agl during the event. Contours of the potential temperature every $1 \mathrm{~K}$ are also included in the figure. At MP5, the jet becomes well defined below $200 \mathrm{~m}$ agl at $\approx 17: 00$ and, although it widens and thins during the shown period, its peak does not vary much in height. The ABL height estimation based on $\mathrm{Ri}_{b}$ at MP5 is also plotted, and as shown, it follows very closely the peak of the jet at MP5 during the whole period. Such an agreement provides us confidence on the accuracy of the Fr computations upstream (MP5).

This article is protected by copyright. All rights reserved. 


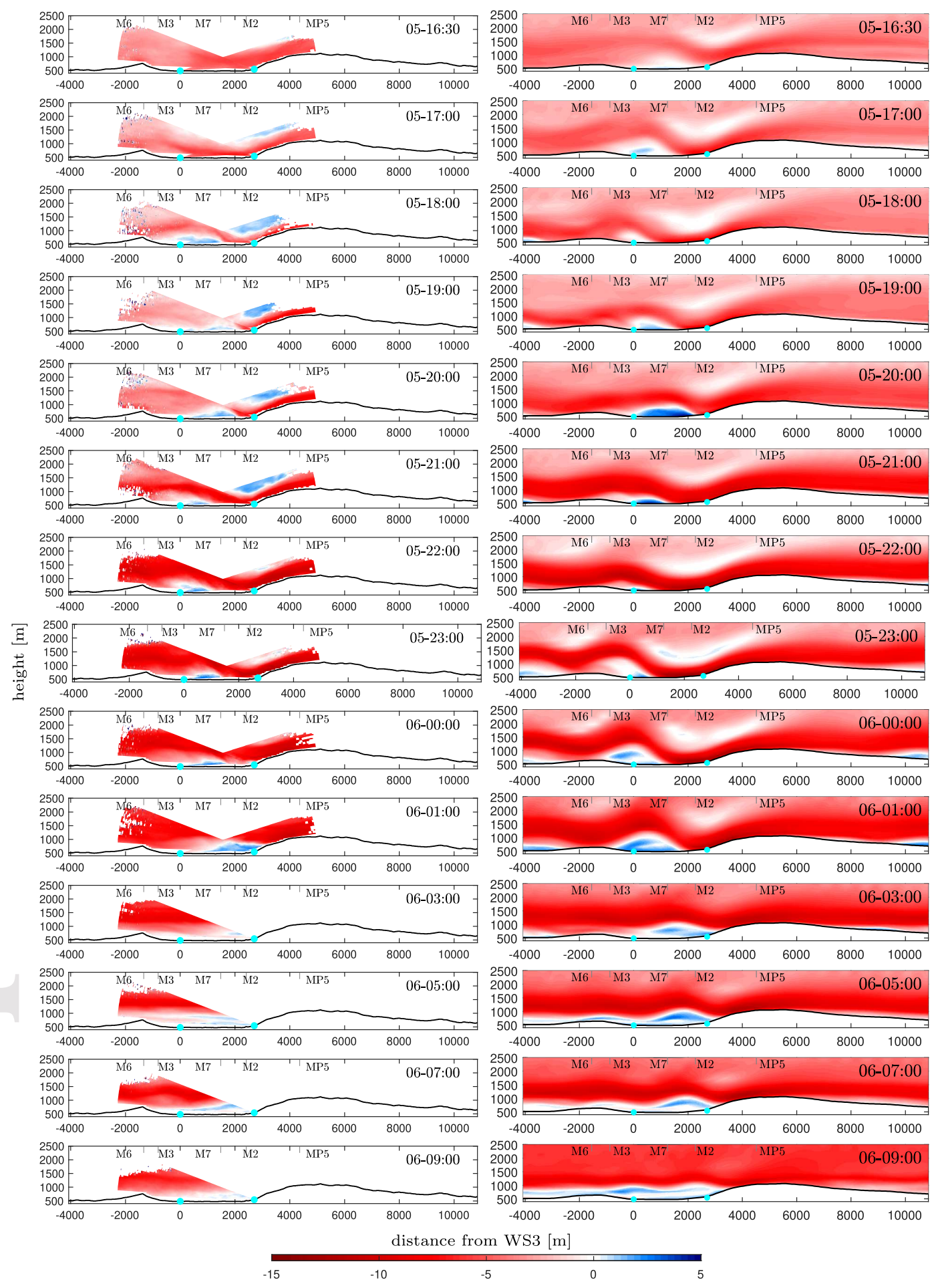

Figure 4. Radial velocities retrieved by the scanning lidar systems (left frames) and simulated horizontal velocities (right frames) for different periods throughout the two days along the extended transect. The colorbar indicates the velocity in $\mathrm{m} \mathrm{s}^{-1}$. The positions of the masts (projected onto the transect) are also indicated. Other details are given in the text 

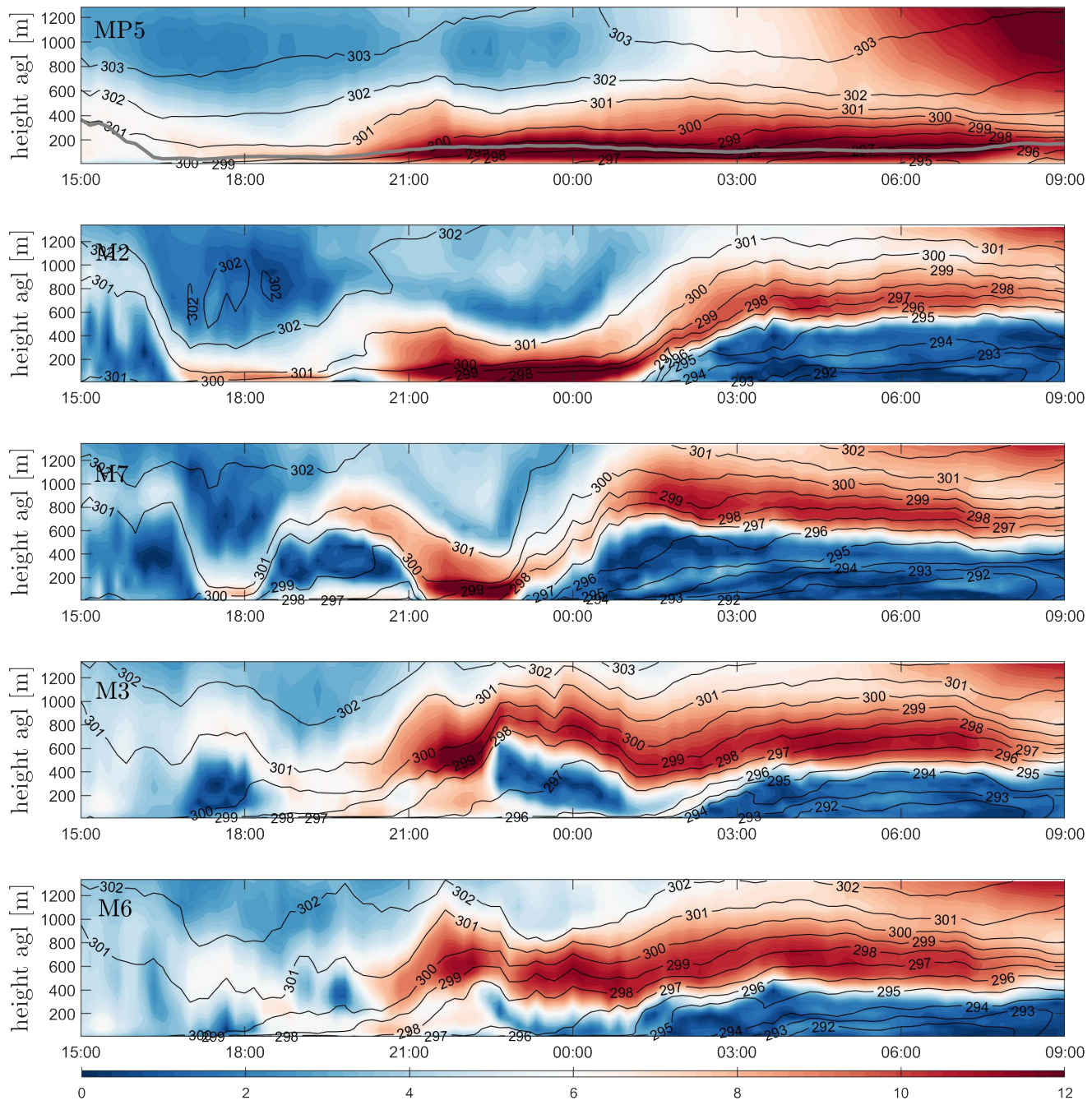

Figure 5. Time development of the simulated wind speed at the mast positions. The colorbar indicates the wind speed in $\mathrm{m} \mathrm{s}^{-1}$. Potential temperature contours are shown in black lines. The ABL height estimated from the simulation outputs at the MP5 position is also indicated in the top frame (grey line) 
The development of the downslope winds is clearly seen at the M2 position. The jet is below $200 \mathrm{~m}$ agl at 17:00-01:00, then it rises until $\approx 03: 00$, and remains relatively steady at $\approx 800 \mathrm{~m}$. Thus, the hydraulic jump occurs downstream of M2 before 01:00, and between 01:00 and 03:00 the jump is being 'replaced' by lee-wave activity as we also illustrate in the right frames of Fig. 4. At M7 we observe a similar behavior of the jet to that at M2 up to slightly after 18:00. From about 18:00 to 21:00, the jet seems to rise up to $\approx 800 \mathrm{~m}$ agl and fall close to the ground and, before $23: 00$, it ascends back to $\approx 800$ $\mathrm{m}$ where it remains relatively steady. At M3 and M6, we see a clear jet moving with height from slightly before 21:00 to close to 03:00 where it remains rather steady. Based on our distinction between 'jump' and 'lee wave', the elevated jet at M7, M3 and M6 at about 18:00-21:00 and 23:00-03:00 is a hydraulic jump; from 03:00 onwards we are looking at lee-wave activity.

As illustrated, the potential temperature contours follow the development of the jet closely, particularly at all positions downstream of MP5. For those positions, the jet nose is located close to the $299 \mathrm{~K}$ contour; however, estimations of the ABL height based on $\mathrm{Ri}_{b}$ do not agree with the jet peaks (not shown). When the jet is close to the ground, e.g., between 21:00 and 01:00 at M2, the ABL height estimate follows the jet nose but when the jet peaks above 200-300 m, the ABL appears very thin using such estimate. This is because at these downstream positions, the vertical gradients of potential temperature and wind speed are rather high and low, respectively, and thus the $\mathrm{Ri}_{b}$ values are high and positive close to the surface. The potential temperature contours also show that downstream of MP5, the flow cannot be represented by a two-layer model flow and, thus, the limitations of computing Fr from Eqn. (1) (Durran, 2003).

\subsection{Vertical profiles}

Figure 6 illustrates observed and simulated vertical profiles of both mean wind speed (top frames) and potential temperature (bottom frames) at six 10-min periods separated 3 -hr each to cover the event. The simulations are plotted up to $800 \mathrm{~m}$ agl as wave activity is present at this level. One can notice, at least qualitatively, that the agreement between observations and simulations seems better for the wind speed than for the potential temperature, with the simulations showing a overall consistent cold bias at all levels and mast positions; the bias seems to be lowest at MP5 and decreasing close to the surface. At 15:00, observations of potential temperature (approximated using the dryadiabatic lapse rate) at all positions other than MP5 are above $304 \mathrm{~K}$ and thus not shown for visualization purposes.

Except for the wind speed profiles at 15:00, the simulations show a jet within the first $800 \mathrm{~m}$ agl at all positions. At 18:00 the downslope winds at M2 are stronger than those at MP5 within the first $100 \mathrm{~m}$ (also seen in the mast measurements) and at M7 the values are nearly as those of MP5; the downslope winds thus reached the M7 location. At 21:00 the simulated jet at M3 and M6 is at $\approx 400 \mathrm{~m}$ agl and at these positions and for the rest of the night, this will be the minimum height of the jet; for M7 there are jets at 100 and $300 \mathrm{~m}$ agl. At 00:00, the simulations continue to show strong downslope winds at M2, which is clearly not noticed from the observations. At this time, the lee-wave regime starts 'replacing' the hydraulic jump regime.

At 15:00, the simulated temperature profiles depict unstable atmospheric conditions close to the surface and a stable layer starting around $400 \mathrm{~m}$ agl at MP5, which closely matches the estimated ABL height. The simulations then show a clear stable atmosphere from 18:00 to 06:00, which is also the type of atmosphere that the observed profiles indicate, although the differences of temperatures between vertical levels are more abrupt in the observations than in the simulated values. At 09:00, the atmosphere becomes unstable close to the surface at all mast positions but with low inversions, particularly at MP5, which also match the ABL-height estimation closely.

This article is protected by copyright. All rights reserved. 

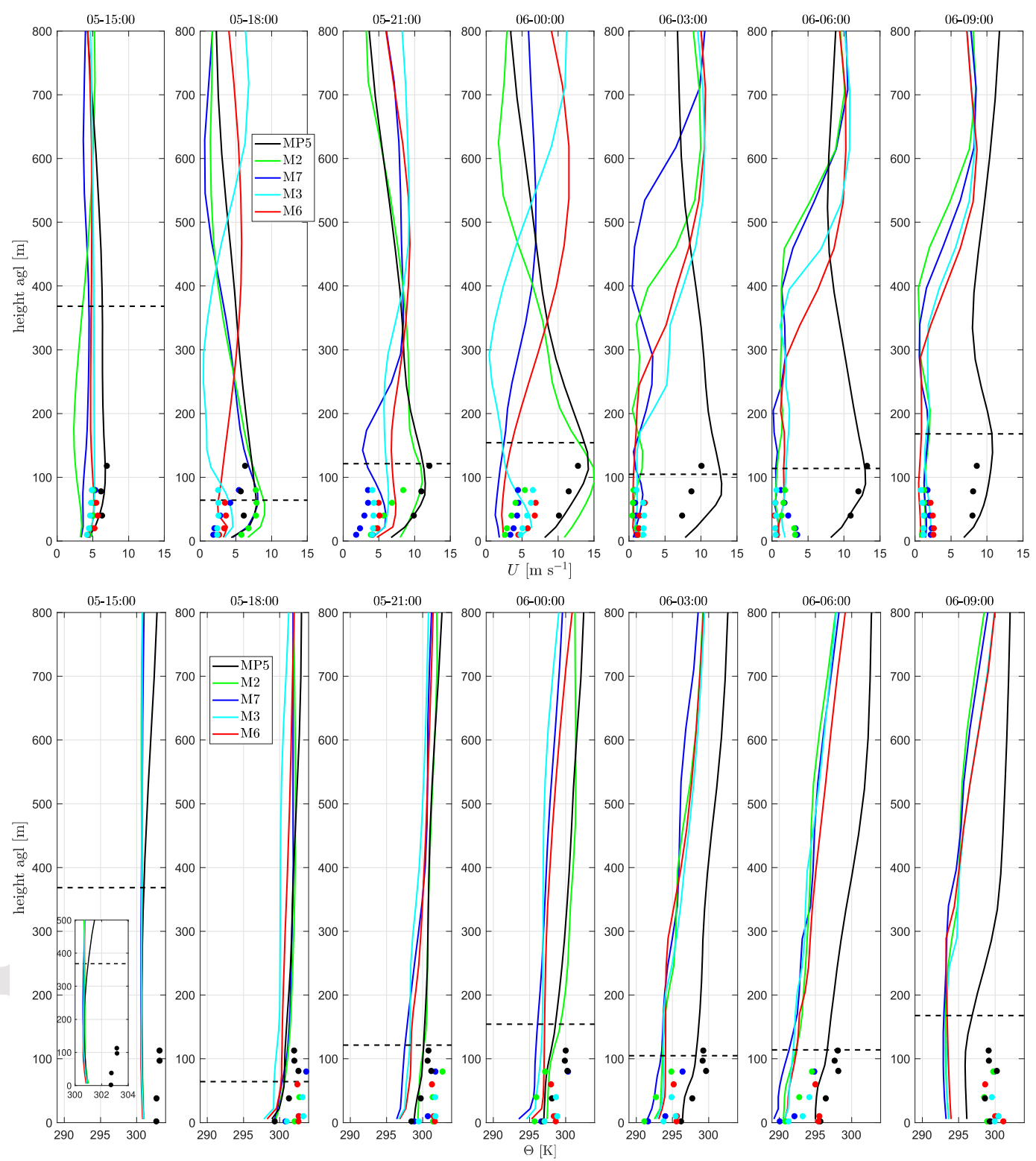

Figure 6. Simulated (solid lines) and observed (markers) vertical profiles of wind speed (top frames) and potential temperature (bottom frames) at the different mast positions for a number of 10-min periods over the two days. The insert on the bottom-left panel shows the details of the profiles close to the ground. The ABL height estimated at MP5 is also shown (black dashed line) 


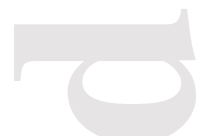

\subsection{Time series}

Figure 7 illustrates time series of a number of simulated and observed variables during the 24-hr period covering the jump event. The estimations of the dimensionless mountain height $H / h$, where $H=582.89 \mathrm{~m}$ is the maximum height difference along the extended transect, and Fr, based on the outputs of the simulation, are also shown for the MP5 position.
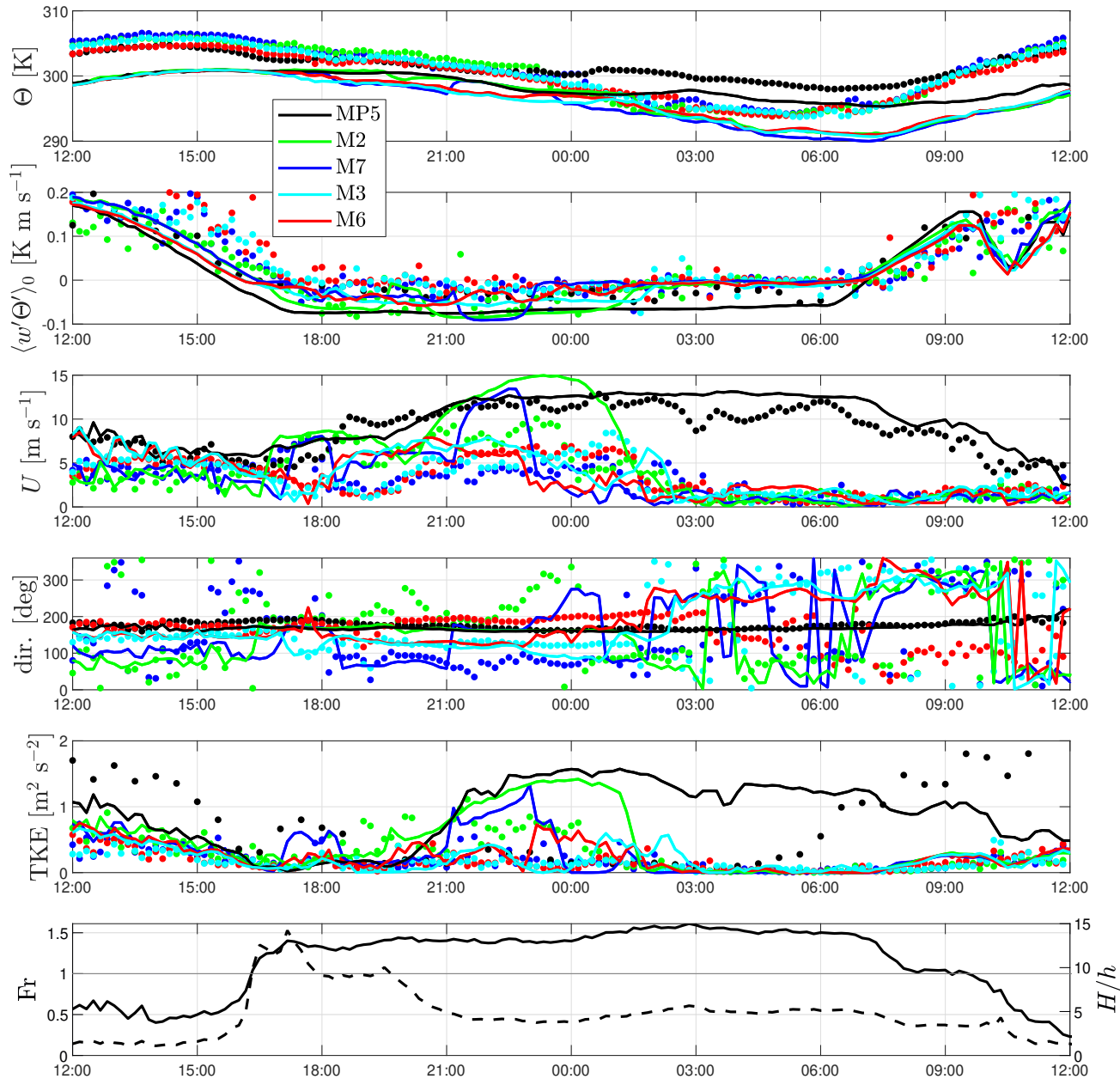

Figure 7. Simulated (solid lines) and observed (markers) time series of potential temperature, surface heat flux, wind speed, direction, TKE, Froude number (solid line)/dimensionless mountain height (dashed line) from top to bottom frame, respectively, at the different mast positions. The observed potential temperatures for M7, M2 and MP5 are at $80 \mathrm{~m}$, for M6 at $60 \mathrm{~m}$, and for M3 at $40 \mathrm{~m}$. The observed wind speeds and directions for all masts are at $80 \mathrm{~m}$, except at M6, where observations are at $60 \mathrm{~m}$. The observed TKE values are at $40 \mathrm{~m}$ and scaled by a factor of five for better visualization. The simulated TKE value corresponds to the subgrid-scale part only. The simulations are extracted at 10,40,56, and $72 \mathrm{~m}$ when compared to the observations at 10 , 40, 60, and $80 \mathrm{~m}$, respectively

We observe that the trends in observed potential temperature are followed by the simulations with the general cold bias in the model output. The observed departure at midnight of the MP5 potential temperature from those at the other positions is well cap-

This article is protected by copyright. All rights reserved. 
tured by the model. The simulated surface heat flux $\left\langle w^{\prime} \Theta^{\prime}\right\rangle_{0}$ shows the same trend of the observations (all from instruments at $10 \mathrm{~m}$ agl but MP5, which uses one at $40 \mathrm{~m} \mathrm{agl}$ ), following an ideal clear-sky pattern during the first day, and becomes negative around 16:30 (earlier for MP5 than for the other positions), which is about the time where the jump was first observed. It becomes positive around 07:00 and, as we show in Sect. 4.1, waves on the lee side of the Alaiz mountain still appear in the simulation until about 11:00 (although results are shown until 09:00).

When compared to the observations, wind speeds are qualitatively well simulated by the model. MP5's simulated wind speed, in particular, agrees very well with the observations; from the simulations at $80 \mathrm{~m}$ agl, the wind speed at MP5 is the highest except for a short period before 18:00 and at 21:00-01:00 where the highest wind speed at $80 \mathrm{~m}$ agl is simulated at the lee side of the mountain (M2). For the other positions, simulated and observed wind speeds agree best under low wind conditions. Between the periods 17:00-18:30 and 21:00-23:00, the simulation shows the jump further downstream of M7 as the wind speed at this mast is nearly as high as that at MP5 and M2. Both observations and simulations show steady southerly surface winds during the 24 -hr period at the mountain top (MP5). The observations show that at the base of the mountain and at the valley (M2 and M7), winds are either west or east before 16:30 (simulations show easterly winds at these positions only) and the simulations show that winds at M2 and M7 become south for the periods when wind speeds at these two masts are close to those at MP5, further demonstrating that the downslope winds from the Alaiz mountain reach M7 and that the jump occurs downstream of M7. Observations and simulations at the positions close to the Tajonar ridge (M3 and M6) show close to south winds until close to midnight where simulated winds become mostly westerly at these two positions.

Hydraulic jumps are highly turbulent (Gohm et al., 2008; Strauss et al., 2015) and, therefore, we also show the simulated subgrid-scale turbulent kinetic energy (TKE) at $40 \mathrm{~m}$ agl. The resolved part of the TKE is damped and most of the time inhibited, particularly during the night time, due to the smooth mesoscale flow driving the LES (thus not shown). The subgrid-scale TKE follows the trends of the 80-m agl wind speed at all mast positions, with largest values near midnight at MP5 and M2, relatively high compared to what we expect for such a stable atmosphere. The observed TKE at MP5 shows high values during daytime and rather low values during the night. The observed TKE at M2, and to some degree that at M7, have values distinctly higher during the night than during the day, following the behavior of the subgrid-scale TKE at these two positions. Particularly within the period between 21:00 and 22:00, the highest TKE values are observed at M2, which is right the period within which the jump is observed deepest into the Elorz valley (see Fig. 4-left middle frames).

The time evolution of Fr (solid line in Fig. 7-bottom frame) at the Alaiz mountain top (MP5) indicates the wave activity in the simulated atmosphere. At about 16:30, the flow becomes supercritical at MP5, which is right at the time of the first observed and simulated hydraulic jump, as we show in Sect. 4.1. After reaching a value close to 1.5, Fr does not vary largely until it decreases to about 1.0 around 08:00, and finally, drops below 1.0 at about 10:00. The parameter $H / h$ also shows a sharp increase when the flow becomes supercritical; when $\mathrm{Fr}=1$ the ABL height is only about a tenth of the Alaiz mountain height. At 21:00 $H / h$ returns to values nearly as low as those before the flow became supercritical and the ABL does not thin at the Alaiz mountain top any longer.

\subsection{Cross sections}

Contour plots of the simulated meridional velocity along six $\approx 11$-km long cross sections at close to right angles to the extended transect, and separated about $1850 \mathrm{~m}$, are illustrated in Fig. 8 to analyze the extent of the hydraulic jump longitude-wise. The merid-

This article is protected by copyright. All rights reserved. 
ional velocity corresponds to the instantaneous output of the simulation on October 5 at 21:00, where the simulated horizontal velocity (Fig. 4-right frames) shows a clear intense jump that, on the extended transect, appears around the middle of the Elorz valley. The jump reaches an elevation $\approx 1500 \mathrm{~m}$ above mean sea level at the highest position close to the wind side of the Tajonar ridge base.

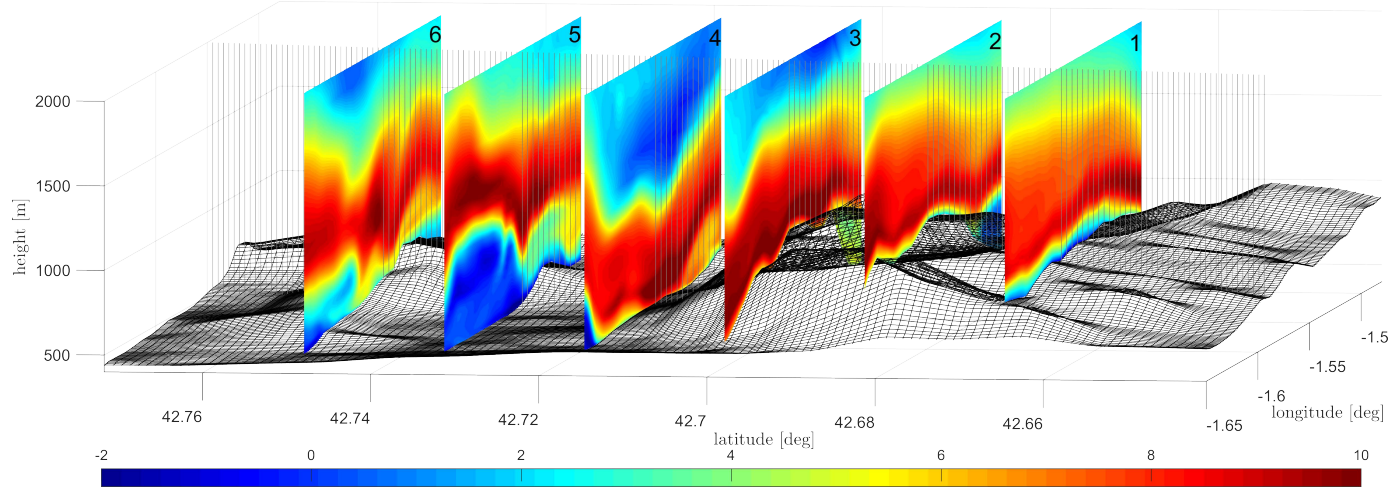

Figure 8. Simulated meridional velocity along cross sections to the extended transect (shown as vertical gray lines) at six latitudes on the Alaiz experimental area on October 5 at 21:00. The simulated elevation of the area is shown as a black wireframe. The colorbar indicates the velocity in $\mathrm{m} \mathrm{s}^{-1}$. Other details are given in the text

At the southernmost cross section (1), which is $3174 \mathrm{~m}$ south (and upstream) of the MP5 position, the simulation shows a relatively, longitudinal-wise, homogeneous velocity field with a distinct jet nose at about $300 \mathrm{~m}$ agl. Although it is not shown, the zonal wind component at the jet area is nearly zero. Moving northwards to the next cross section (2), which is $1323 \mathrm{~m}$ south of the MP5 position, the picture is similar but, in this case, the jet nose is located about $165 \mathrm{~m}$ agl. One can notice that on the easternmost area of this cross section (2) and close to the ground, the meridional velocity is negative indicating reverse flow as the elevation profile decreases on those locations compared to the elevation profile of the upstream cross section (1).

The next cross section (3), which is about $528 \mathrm{~m}$ north (and downstream) of the MP5 position, is at the beginning of the lee side of the Alaiz mountain range. There downslope winds, with an intense jet nose about $92 \mathrm{~m}$ agl, are simulated nearly at all locations, except for the area east of the extended transect in which the jet stays at similar heights as those of the upstream cross section (2). Along the first three cross sections, which are upstream of the lee side of the mountain range, the flow is generally supercritical ( $\mathrm{Fr}>$ 1) with Fr values increasing both latitude-wise and westwards.

Moving northwards to the next cross section (4), which is $2380 \mathrm{~m}$ north of the MP5 position, we are some hundreds of meters from the base of the Alaiz mountain (at the beginning of the Elorz valley) where the elevation profile does not any longer change much eastwards. East of the crossing of the extended transect the jet remains at nearly the same heights as observed on the same area of the upstream section (3). In the middle of the cross section (4), the jet nose is close to the ground as a result of the downslope winds reaching the valley and the jet strength is the highest of all cross sections. On the westernmost area of the cross section (4), the jet nose rises up to about $550 \mathrm{~m}$ agl showing that the hydraulic jump also occurs at this position, which is downstream of the last extension of the Alaiz mountain range (these westernmost positions are already located about $2000 \mathrm{~m}$ from the base of the mountain).

This article is protected by copyright. All rights reserved. 
The next cross section (5) portrays the situation within the middle of the Elorz valley mostly. The simulation shows the elevated jet from the hydraulic jump at most locations eastwards. East of the crossing with the extended transect, the jet nose reaches around $800 \mathrm{~m}$ agl, which is higher than the location of the jet nose on the extended transect (Fig. 4-right frames) at the same time. Finally, the northernmost cross section (6) shows the situation over the Tajonar ridge. Close to the middle of the section and moving westwards, the jet nose is at lower levels (400-500 m agl) and slightly decreases strength. For the northern cross sections (4-6), estimating the ABL height via the $\mathrm{Ri}_{b}$ approach is limited, due to the low and high vertical gradients of temperature and wind speed close to the ground and, thus, computing Fr is challenging. Although not shown, at this particular time and three cross sections, the flow is supercritical close to the location of the transect (middle of the cross section) and becomes subcritical the farther we move east and west within the cross section.

It is important to notice that for all these cross sections (and for the whole innermost domain), the winds at about $2000 \mathrm{~m}$ or at higher levels are from the west, whereas at low levels within the areas below the jet they are from the east or southeast. Particularly, at the southern areas of the Tajonar ridge, the winds close to the ground have a strong zonal component $\left(>7 \mathrm{~m} \mathrm{~s}^{-1}\right)$. As we already mentioned, before the hydraulic jump event, surface winds over the Alaiz mountain range are south but they are southeasterly and easterly over the Elorz valley. At 21:00 and close to the surface, downslope south winds reach up to the middle of the Elorz valley and meet strong east winds flowing through the gap between the Tajonar ridge and the Alaiz mountain range. At the same time but at $\approx 600 \mathrm{~m}$ agl, winds are south within the whole innermost domain and at $\approx 1600 \mathrm{~m}$ agl they are west. At 09:00, surface winds over the Alaiz mountain range continue to be south but those over the Elorz valley become west as those simulated at $\approx 1600 \mathrm{~m}$ agl or above.

\subsection{A flow regime diagram}

Given the previous analysis and results from both observations and simulations, the phenomena taking place at Alaiz can be separated into two periods. First, a hydraulic jump takes place between 16:30 and 02:15 and, second, lee-wave activity takes over lasting slightly after 09:00. Within these two periods, one could also say that when downslope winds are still present close or further downstream of the scanning lidar location at the base of the Alaiz mountain, we have a distinct atmospheric hydraulic jump and that we talk about mountain-wave activity otherwise. Fr, computed from the simulation outputs at the MP5 position, is above unity within these two periods and remains below unity for the rest of the time within the 24 -hr period. Therefore, we are interested in understanding the mechanisms leading to downslope winds reaching the base of the Alaiz mountain (and further into the valley) and those leading to lee-wave activity.

Figure 9 illustrates a flow diagram based on simulation outputs for the periods in which Fr $>1$ at the mountain top (MP5). The diagram portrays the relation between the upstream (MP5) and downstream (M2) values of the ratio of the depth-average mean wind speed to the depth-average Brunt-Väisälä frequency both ratios non-dimensionalized by the mountain height $H$. Such dimensionless parameter is also sometimes referred to as Froude number. The Brunt-Väisälä frequency is computed at all half levels of the simulations as

$$
N=\sqrt{\frac{g}{\Theta} \frac{\Delta \Theta}{\Delta z},}
$$

where $\Delta$ represents the difference between two consecutive vertical levels. Note that the depth-averages in Fig. 9 are performed over the extent of the mountain height $H$ instead of the ABL height $h$ from which Fr was computed at MP5.

As shown in Fig. 9, at MP5 and M2 these dimensionless parameters can be above and below unity during the period in which Fr $>1$ at MP5. At MP5 this parameter

This article is protected by copyright. All rights reserved. 


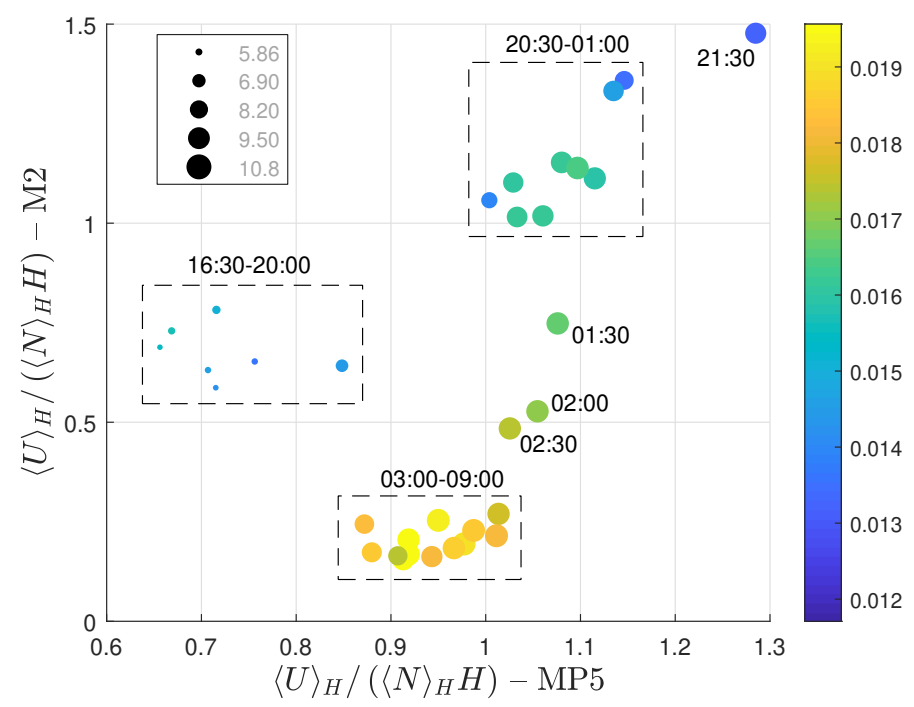

Figure 9. A flow regime diagram based on the simulations outputs within the period where the flow is supercritical at the Alaiz mountain top. Only values on the hour and on the half hour are shown for better visualization. The size of the circle indicates the depth-average wind speed in $\mathrm{m} \mathrm{s}^{-1}$ (see legend at the top left) and the colorbar the depth-average Brunt-Väisälä frequency at MP5 in $\mathrm{s}^{-1}$

alone cannot be used to distinguish between a hydraulic jump and a lee wave case. However, the period portraying lee waves shows the lowest values at M2. Further, the leewave periods are characterized by the highest depth-average Brunt-Väisälä frequencies at MP5 (colors in Fig. 9); they are nearly as twice as those corresponding to the values at the start of the hydraulic jump event. Periods portraying lee waves are characterized by high depth-average wind speeds $\left(\approx 10 \mathrm{~m} \mathrm{~s}^{-1}\right)$ but the hydraulic jump is portrayed within the range of depth-average wind speeds. It should be noted that we were unsuccessful when using several parameters to construct a flow diagram in which the two types of flow regimes could be distinguished based on the upstream flow conditions only, i.a., the dimensionless parameter $\mathrm{NH} / U$ (estimated at specific vertical levels), which is another form for the inverse of a Froude number that shows the same behavior as the Scorer parameter $\left(\approx N^{2} / U^{2}\right)$, and a depth-average Brunt-Väisälä frequency but over the ABL height, partly because of the thin ABL at MP5. We can notice that downslope winds during 16:3020:00, which turn further downstream into a hydraulic jump, are a result of a low depthaverage wind speed at the mountain top (but 'fast' enough for the flow to become supercritical). After 20:00 when the flow moves 'faster', both a hydraulic jump and lee waves may occur; if at the mountain top the air parcels experience vertical displacements at a high frequency, with the consequence of restoring forces to act on those parcels, lee waves are portrayed.

The findings in Fig. 9 can be summarized as follows. At the beginning of the night, the flow can penetrate deeply into the valley because, although the wind is not strong, the stability is not that high. This leads to occurrence of hydraulic jumps at locations downstream of WS5. During the night, the increasing stability of the flow inhibits the penetration of the flow into the valley and thus the flow separates farther upstream.

This article is protected by copyright. All rights reserved. 


\section{Conclusions and discussion}

Radial velocity observations performed with two scanning lidars portray a distinct atmospheric hydraulic jump taking place over the lee side of the Alaiz mountain range and over the Elorz valley in the northeast of Spain during a clear-sky autumnal afternoon. Real-time atmospheric simulations performed with the WRF model are capable of reproducing in high detail the spatial characteristics and timing of the jump and the flow over the area, as demonstrated by comparison of the simulation outputs with observations from the lidars and from meteorological instruments on a series of masts spread over the area.

Both lidar radial velocity observations and simulations of the horizontal velocity show that the hydraulic jump starts at about 16:30, which, based on the analysis of the simulation outputs, corresponds to the time when the atmosphere becomes stable and the flow at the Alaiz mountain top experiences the transition from subcritical $(\mathrm{Fr}<1)$ to supercritical $(\mathrm{Fr}>1)$. Fr is here an ABL-depth average value computed from the simulation outputs only. The ABL depth is computed using the bulk Richardson number approach, which is traditionally used in numerical weather prediction models. From the simulation outputs at the Alaiz mountain top, the ABL depth matches very well the location of the peak of the jet. At the time of the flow transition, the ABL thins up to a tenth of the mountain height.

The simulations show that the jump lasts about 10 hours until it moves close to the Alaiz mountain top. From 01:00, the simulations complement the scanning lidar observations and show that between 01:00 and 03:00, lee-wave activity takes over until late in the morning. Downslope winds over the lee side of the Alaiz mountain, which eventually develop into a hydraulic jump further downstream, appear under a flow regime with relatively high ratios of depth-average flow speeds to depth-average Brunt-Väisälä frequencies computed downstream of the mountain top, whereas both the hydraulic jump and lee waves occur within the range of values computed upstream. Based on upstream conditions only, lee waves occur during periods in which the depth-average Brunt-Väisälä frequency is high mainly because the flow cannot penetrate the valley at such degree of stability.

It is important to mention that when looking at the results of the domain that runs at a 333.33-m resolution, we can still distinguish the hydraulic jump and the wave activity clearly but without the spatial details and the timing of the results that correspond to the innermost domain. We also tried to test the limitations of the WRF PBL schemes in simulating the jump event by repeating the simulations but replacing the LES with PBL domains at the same horizontal resolution (we only tried the MYNN PBL scheme as for the three outermost domains). Any attempt to use a PBL scheme for the two innermost domains failed at the time where other parametrizations are called by the model (e.g., radiation). Increasing the height of the first vertical level of the model, which from our experience aids at avoiding numerical errors particularly over hilly terrain using the WRF model, did not help.

Given both that the upstream conditions, i.e., those at the top of the Alaiz mountain, are key for the development of the hydraulic jump, and that most of the high elevation terrain in the simulation corresponds to the same land use class, i.e., deciduous broad leaf forest, we also performed a new simulation with a different roughness length value assigned to that land use class. The original simulation used a value of $0.5 \mathrm{~m}$, whereas the new one used a value of $0.05 \mathrm{~m}$. The new simulation shows the hydraulic jump and lee-wave activity nearly with the same qualitative dynamics and general characteristics as the original simulation. Compared to the latter, the wind speeds of the new simulation at the mast positions are generally slightly higher, the downslope winds are also stronger, and the jump event takes place downstream of M7 (at the valley) during a longer period. The wind directions before 00:00 are also steadily south at all mast positions com- 
pared to the more fluctuating behavior shown at M2 and M7 in the original runs. These analyses and sensitivity studies show that the modelling of mountain waves on the lee side of the Alaiz mountain depends mostly on three ingredients: first, capturing the profile of the mountain (gentle windward and steep leeward slope), second, ABL winds perpendicular to the mountain/ridge line, and, third, the model being able to capture the atmospheric stability conditions at the mountain top. It will therefore be interesting to attempt the modeling of the flow over Alaiz using idealized simulations in the near future.

We chose the ABL depth to define the extension of the lowest layer of a two-layer flow model because, first, at the mountain top the computed ABL depth agrees well with the jet locations and, second, the Froude number, derived from ABL-depth average parameters, shows the transition from subcritical to supercritical flow at the mountain top timely. The height of the flow reversal could be another choice as seen from the radial velocity observations; however, reverse flow is not easily distinguished from the simulation outputs at the mountain top.

One might consider that the 111.11-m resolution domain is too coarse for the modelling the flow over terrain of this complexity. It definitively is, but for the flow conditions that we study, the terrain input captures the profile of the Alaiz mountain well, as shown in Fig. 3-bottom. This horizontal resolution is however not sufficient to capture the details of the flow over the Tajonar ridge. Further, with this horizontal resolution, the recommended time step is about six times that we used for the simulations as larger time steps led to numerical instabilities.

It is also important to note that when performing these multi-scale simulations, we downscale through the "terra incognita" scales (Wyngaard, 2004). It is therefore of interest to evaluate in future work whether some approaches, e.g., those based on threedimensional ABL parametrizations (Kosović et al., 2020), explicit filtering and reconstruction (Simon et al., 2019), and scale-awareness (Honnert et al., 2011), can help improving the numerical modeling of hydraulic jumps and mountain waves.

Other periods portraying atmospheric hydraulic jumps were spotted during the Alaiz experiment. During the evenings of September 15, 20 and 26 and November 10, the mast observations show southerly, stable stratified, and supercritical flow with strong speeds $\left(>5 \mathrm{~m} \mathrm{~s}^{-1}\right)$ at the Alaiz mountain top. The RHI scans confirm the presence of hydraulic jumps and lee-wave activity, which might be further analyzed to help understanding the conditions at which these phenomena occur and their impact on, e.g., wind energy as the wind resources of this area are highly exploited for that purpose.

\section{Acknowledgments}

We acknowledge two anonymous reviewers for their suggestions, which improve the manuscript. This work was partly funded by the Ministry of Foreign Affairs of Denmark and administered by the Danida Fellowship Centre through the "Multi-scale and Model-Chain Evaluation of Wind Atlases" (MEWA) project. We would also like to acknowledge the European Commission that partly funded the New European Wind Atlas (NEWA) project through FP7, in which the Alaiz experiment took place.

\section{Data availability statement}

The observational data associated with this work is accessible from Santos et al. (2019). We plan to use the same open-access data-sharing platform of the Technical University of Denmark (https://data.dtu.dk/) for the simulated data if required. An animation of the hydraulic jump episode can be openly accessed at https://doi.org/10 .11583/DTU.13003187 (Santos \& Peña, 2020).

This article is protected by copyright. All rights reserved. 


\section{References}

Anderson, J. R., Hardy, E. E., Roach, J. T., \& Witmer, R. E. (1976). A land use and land cover classification system for use with remote sensor data (Tech. Rep. No. 964). US Geological Survey.

Badger, J., Frank, H., Hahmann, A. N., \& Giebel, G. (2014). Wind-climate estimation based on mesoscale and microscale modeling: stastical-dynamical downscaling for wind energy applications. J. Appl. Meteor. Climat., 53, 19011919.

C3S. (2018). ERA5: Fifth generation of ECMWF atmospheric reanalyses of the global climate. Copernicus Climate Change Service Climate Data Store (CDS). (https://cds.climate.copernicus.eu/. Accessed: 17.09.2019)

Cantero, E., Guillen, F. B., Rodrigo, J. S., Santos, P., Mann, J., Vasiljevic, N., ... Cuxart, J. (2019). Alaiz Experiment (ALEX17): Campaign and Data Report (Tech. Rep. No. NEWA deliverable report D2.21).

Chanson, H. (2009). Current knowledge in hydraulic jumps and related phenomena. A survey of experimental results. Eur. J. Mech. Fluids, 28B, 191-210.

Clarke, R. H. (1972). The morning glory: an atmospheric hydraulic jump. J. Appl. Meteor., 11, 304-311.

Copernicus Land Monitoring Service. (2018). CORINE land cover. (https://land .copernicus.eu/pan-european/corine-land-cover. Accessed: 17.09.2019)

Danielson, J. J., \& Gesch, D. B. (2011). Global multi-resolution terrain elevation data 2020 (GMTED2010) (Tech. Rep. No. 2011-1073). US Geological Survey.

Deardorff, J. W. (1980). Stratocumulus-capped mixed layers derived from a threedimensional model. Boundary-Layer Meteorol., 18, 495-527.

Donlon, C. J., Martin, M., Stark, J. D., Roberts-Jones, J., Fiedler, E., \& Wimmer, W. (2012). The Operational Sea Surface Temperature and Sea Ice analysis (OSTIA) system. Remote Sens. Environ., 116, 140-158.

Durran, D. (2003). Downslope winds. In J. R. Holton (Ed.), Encyclopedia of atmospheric sciences (p. 644 - 650). Oxford: Academic Press.

Gohm, A., Mayr, G. J., Fix, A., \& Giez, A. (2008). On the onset of bora and the formation of rotors and jumps near a mountain gap. Q. J. R. Meteorol. Soc., $164,21-46$.

Holmboe, J., \& Klieforth, H. (1957). Investigation of mountain lee waves and the air flow over the Sierra Nevada (Tech. Rep. No. 133606). Dept. of Meteorology, University of California, Los Angeles.

Hong, S.-Y., Dudhia, J., \& Chen, S.-H. (2004). A revised approach to ice microphysical processes for the bulk parameterization of clouds and precipitation. Mon. Wea. Rev, 132, 103-120.

Honnert, R., Masson, V., \& Couvreux, F. (2011). A diagnostic for evaluating the representation of turbulence in atmospheric models at the kilometric scale. $J$. Atmos. Sci., 68, 3112-3131.

Iacono, M. J., Delamere, J. S., Mlawer, E. J., Shephard, M. W., Clough, S. A., \& Collins, W. D. (2008). Radiative forcing by long-lived greenhouse gases: calculations with the AER radiative transfer models. J. Geophys. Res., 113, D13103.

Juliano, T. W., Parish, T. R., Rahn, D. A., \& Leon, D. C. (2017). An atmospheric hydraulic jump in the Santa Barbara Channel. J. Appl. Meteor. Climat., 56, 2981-2998.

Kain, J. S. (2004). The Kain-Fritsch convective parameterization: an update. J. Appl. Meteor. Climat., 43, 170-181.

Kosović, B., Munoz, P. J., Juliano, T. W., Martilli, A., Eghdami, M., Barros, A. P., \& Haupt, S. E. (2020). Three-dimensional planetary boundary layer parameterization for high-resolution mesoscale simulations. J. Phys.: Conf. Series, 1452, 012080 .

This article is protected by copyright. All rights reserved. 
Lehner, M., Whiteman, C. D., Hoch, S. W., Crosmsman, E. T., Jeglum, M. E., Cherukuru, N. W., ... Klein, P. (2016). The METCRAX II Field Experiment: A Study of Downslope Windstorm-Type Flows in Arizona's Meteor Crater. Bull. Amer. Meteor. Soc., 97, 217-235.

Long, R. R. (1953). Some aspects of the flow of stratified fluids. I. A theoretical investigation. Tellus, 5, 42-58.

Lyra, G. (1943). Theorie der stationren Leewellenstrmung in freier Atmosphre. Zeitschr. f. Angewandte Math. u. Mech., 23, 1-28.

Manley, G. (1939). The Helm Wind of Crossfell. Nature, 143, 377.

Mann, J., Angelou, N., Arnqvist, J., Callies, D., Cantero, E., Arroyo, R. C., .. Rogdrigues, C. V. (2017). Complex terrain experiments in the New European Wind Atlas. Phil. Trans R. Soc. A, 375, 20160101.

Mobbs, D., Vosper, S. B., Sheridan, P. F., Cardoso, R., Burton, R. R., Arnold, S. J., ... Gadian, A. M. (2005). Observations of downslope winds and rotors in the Falkand Islands. Q. J. R. Meteorol. Soc., 131, 329-351.

Nakanishi, M., \& Niino, H. (2009). Development of an improved turbulence closure model for the atmospheric boundary layer. J. Meteorol. Soc. Japan, 87, 895912.

Palma, J. M., Silva Lopes, A., Costa Gomes, V. M., Veiga Rodrigues, C., Menke, R., Vasiljević, N., \& Mann, J. (2019). Unravelling the wind flow over highly complex regions through computational modeling and two-dimensional lidar scanning. J. Phys.: Conf. Series, 1222, 012006.

Rayleigh, L. (1883). The form of standing waves on the surface of running water. Proc. Lond. Math. Soc., 15, 69-82.

Richardson, H., Basu, S., \& Holtslag, A. A. M. (2013). Imporving stable boundarylayer height estimation using a stability-dependent critical bulk Richardson number. Boundary-Layer Meteorol., 148, 93-109.

Rodrigo, J. S., Guilln, F. B., Arranz, P. G., Courtney, M. S., Wagner, R., \& Dupont, E. (2013). Multi-site testing and evaluation of remote sensing instruments for wind energy applications. Renew. Energ., 53, 200-210.

Rotunno, R., \& Bryan, G. H. (2018). Numerical simulations of two-layer flow past topography. Part I: The leeside hydraulic jump. J. Atmos. Sci., 75(4), 12311241.

Samuelson, R. M. (1992). Supercritical marine-layer flow along a smoothly varying coastline. J. Atmos. Sci., 49, 1571-1584.

Santos, P., Mann, J., Vasiljevic, N., Cantero, E., Rodrigo, J. S., Borbn, F., .. . Cuxart, J. (2020). The Alaiz experiment: untangling multi-scale stratified flows over complex terrain. Wind Energ. Sci.. (In press)

Santos, P., Mann, J., Vasiljevic, N., Courtney, M., Sanz Rodrigo, J., Cantero, E., ... Cuxart, J. (2019). The Alaiz Experiment (ALEX17): wind field and turbulent fluxes in a large-scale and complex topography with synoptic forcing. Technical University of Denmark. Media. doi: 10.11583/DTU.c.4508597.v1

Santos, P., \& Peña, A. (2020). An atmospheric hydraulic jump at alaiz: numerical simulations and lidar observations. Technical University of Denmark. Media. doi: 10.11583/DTU.13003187.v1

Simon, J. S., Zhou, B., Mirocha, J. D., \& Chow, F. K. (2019). Explicit filtering and reconstruction to reduce grid dependence in convective boundary layer simulations using WRF-LES. Mon. Wea. Rev, 147, 1805-1821.

Strauss, L., Serafin, S., Haimov, S., \& Grubišić, V. (2015). Turbulence in breaking mountain waves and atmospheric rotors estimated from airborne in situ and doppler radar measurements. Q. J. R. Meteorol. Soc., 141, 3207-3225.

Tewari, M., Chen, F., Wang, W., Dudhia, J., LeMone, M. A., Mitchell, K., ... Wegiel, J. (2004). Implementation and verification of the unified Noah land surface model in the WRF model. In 20th conference on weather analysis and forecasting/16th conference on numerical weather prediction. Seattle.

This article is protected by copyright. All rights reserved. 
Wyngaard, J. C. (2004). Toward numerical modeling in the "terra incognita". J. Atmos. Sci., 61, 1816-1826.

This article is protected by copyright. All rights reserved. 